\title{
Las ciudades del cobre y las variaciones de la company town ${ }^{1}$
}

\author{
Eugenio Garcés Feliu \\ Dr. Arquitecto, Profesor Titular en la Facultad \\ de Arquitectura, Diseño y Estudios Urbanos \\ Pontificia Universidad Católica de Chile
}

\section{Ciudades del cobre y company towns}

El desarrollo de la minería del cobre, a lo largo del siglo XX, tuvo como consecuencia la puesta en marcha de un conjunto de operaciones integradas de infraestructura que incluyó la construcción de obras industriales, edificios de equipamiento, viviendas e infraestructuras portuarias, para ocupar y explotar a lo ancho el territorio chileno -normalmente entendido a lo largo de su eje longitudinal- en función de la posición de los recursos y los lugares de embarque del producto, a menudo ubicados en sitios poco propicios al asentamiento humano.

Las ciudades del cobre son producto de la gestión de empresas internacionales que implantaron asentamientos ex-novo en territorios mineros para atender funciones productivas, residenciales y de equipamiento bajo el control exclusivo de la industria, con el propósito de alcanzar resultados de eficiente producción, a partir de una autosuficiencia que hiciese posible el control del conjunto desde un sistema empresarial y jurídico. Al explotar recursos no renovables, las empresas establecieron y establecen su horizonte temporal y productivo a partir del volumen y la ley de los yacimientos y de las estrategias industriales de explotación.

Son herederas, contemporáneas y sucesoras de las company towns, desarrolladas en Europa y Estados Unidos. Buscan máxima concentración de capital y trabajo, viviendas y equipamientos. Asumieron la función productiva como principal programa, en localizaciones territoriales complementarias de las ciudades tradicionales y los territorios rurales. En la actualidad, el término company town se ocupa con amplitud, designando las ciudades industriales de distinto tipo que fueron surgiendo a partir de la Revolución Industrial: industrial villages, cités ouvrières, arbeiter siedlungen, colonias industriales, campamentos mineros. Dal Co (1975) define a la company town como "un ideal que explicita la transformación de la base eco-

1. Este artículo está basado en la investigación FONDECYT 1990485, titulada "Los campamentos de la minería del cobre en Chile . “(1905-2000)", con participación de Eugenio Garcés como investigador responsable, Gustavo Munizaga, Mauricio Baros y Celia Baros como coinvestigadores y Marcelo Cooper como tesista. Una versión anterior de este artículo fue publicada en la revista EURE, Vol XXIX / No 18 / diciembre 2003.
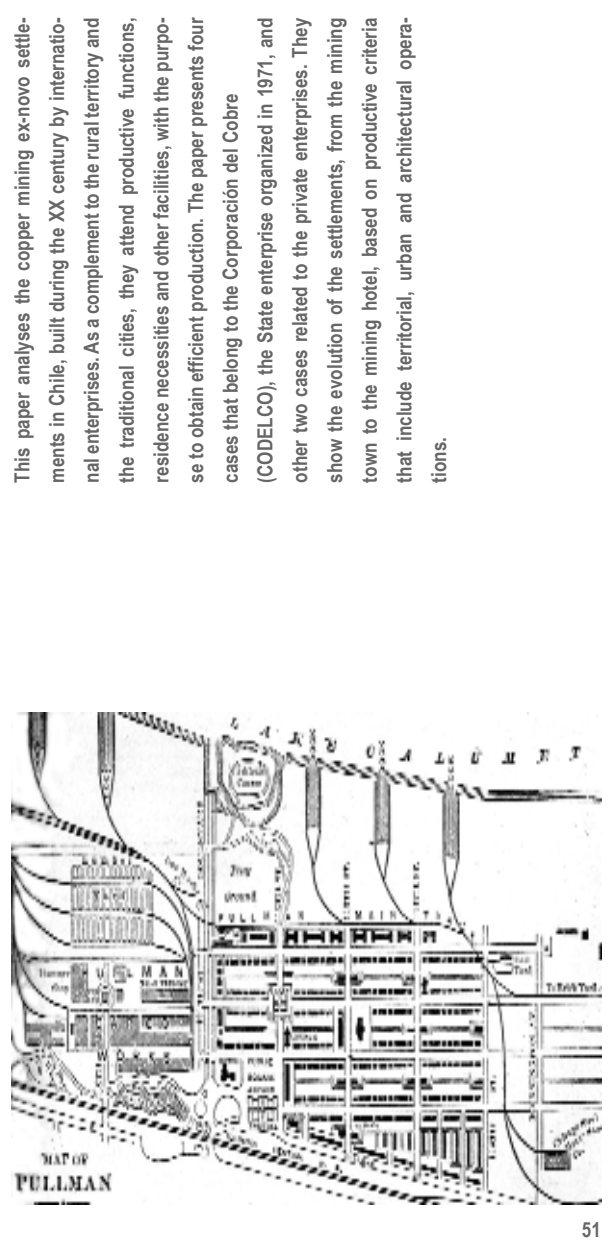
nómica de la nación americana y un modelo que interpreta el mito del primer capitalismo al de una sociedad 'perfecta' al servicio de la manufactura [...] Como modelo urbanístico representa una alternativa completa a la ciudad histórica, no tanto a causa de las formas en las que se estructura, cuanto por el hecho de asumir una única y nueva función, la fábrica, sin otros fines que los de máxima eficiencia productiva, creando un sistema monocultural sin rupturas socioeconómicas".

En la definición del modelo participaron además las propuestas utópicas, destacándose aquellas paradigmáticas por su aporte teórico y proyectual, como lo son el Falansterio de Fourier, la Colonia Hogar Autosuficiente de Owen y la propuesta de Victoria de Buckingham -por citar algunos casos de los llamados socialistas utópicos. A ello hay que agregar, como un contrapunto, los medios técnicos y de infraestructura que desarrolló la Revolución Industrial, permitiendo por primera vez, durante los siglos XIX y XX, la concentración de grandes centros de producción de materias primas en puntos específicos dentro del territorio. De manera que las company towns se instalan en la historia del urbanismo como una manufactura urbana organizada por un proyecto de ingeniería y arquitectura que formaliza y distribuye las edificaciones industriales, los edificios de equipamiento y la residencia, en un conjunto que alcanza una organización física, productiva y social. El modelo es adecuado a la explotación de materias primas y la manufactura industrial, al mismo tiempo que funcional a la modelación de un grupo social excluido de otras actividades y manifestaciones urbanas que aquellas que le entrega la compañía.

Los ejemplos internacionales son muchos: en Estados Unidos, Lowell, Pullman y Tyrone; Saltaire y Bournville en Inglaterra; Zlín en la República Checa; las Salinas de Chaux, Le Creusot y Mulhouse en Francia; la Colonia Güell en Cataluña, España, entre otros. Entre los casos chilenos se encuentran Lota relacionado con la minería del carbón; las oficinas salitreras Humberstone y Santa Laura, cerca de lquique, y Chacabuco, María Elena y Pedro de Valdivia, en la región de Antofagasta (Garcés, 1999); y el campamento Cerro Sombrero, vinculado con la explotación del petróleo, en Tierra del Fuego, entre otros.

Cada uno de los casos de las ciudades del cobre en Chile responde a una organización urbana y productiva que ha oscilado entre una condición arquetípica y su adecuación a determinadas preexistencias topográficas, ambientales y funcionales, llevada a cabo por los departamentos de ingeniería de las empresas mineras, que han demostrando una particular flexibilidad para adaptarse a circunstancias territoriales, económicas, políticas, de manera que las formas de los asentamientos, los tipos, materialidad, cantidad y calidad de las viviendas y de los equipamientos han ido evolucionando con nuevas tipologías, mejores están-

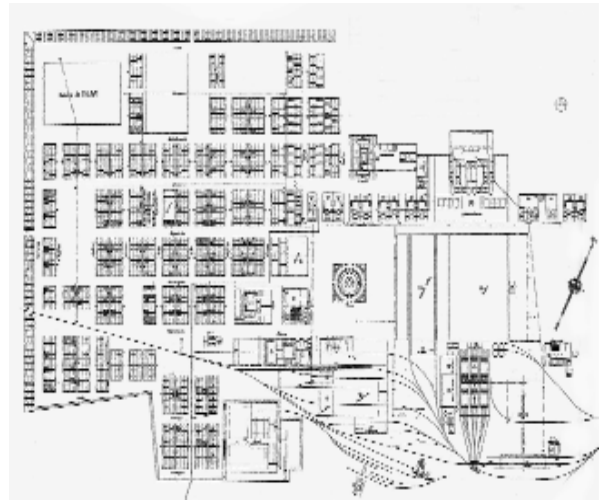


dares y avanzadas técnicas constructivas, las que con el tiempo fueron adoptándose en las ciudades tradicionales. De la participación de arquitectos en los procesos de diseño no se tiene registro, a lo menos hasta los años '60, cuando Raymond Olson firma el proyecto de El Salvador. Desde entonces, los arquitectos han tenido figuración en el diseño del campamento de Saladillo (que no se incluye en este artículo), Cerro Sombrero (mencionado más arriba) y en los nuevos emprendimientos mineros desde los años ' 90 en adelante, así como en los proyectos de edificios singulares, como el hospital de Chuquicamata.

En la actualidad, la concepción original del campamento minero, dotado de viviendas y equipamientos para los trabajadores y sus grupos familiares, ha sido revisada, al llevarse a cabo procesos de traslado de los habitantes a ciudades mayores de las regiones en que operaron, con el consecuente abandono y desmantelamiento del campamento original, dejando en funciones las plantas industriales. La "Operación Valle" que afectó a Sewell, el desalojo que cerró Potrerillos y el "Proyecto Traslado" del campamento de Chuquicamata son ilustradores en este sentido. Se trata de operaciones motivadas por causas diversas: en el caso de Sewell, el cierre del campamento estuvo inserto en la "chilenización" del cobre y el "Plan de expansión" de 1967, una de cuyas propuestas fue la construcción de cerca de 3.000 viviendas para trabajadores y familias en Rancagua y la construcción de la carretera del cobre que unió dicha ciudad con la mina; en el caso de Potrerillos, los argumentos se centraron en la importante contaminación que sufría el campamento, cuyos residentes fueron resituados en El Salvador; en el caso de Chuquicamata, las razones esgrimidas fueron de orden técnico, ya que el desarrollo de las faenas mineras implicaba el avance de las mismas sobre el campamento. La revisión de la company town minera que se llevó a cabo ha supuesto el desarrollo de nuevos modelos, liderado por las empresas privadas, como veremos en los casos de San Lorenzo y Portal del Inca.

De este modo, El Salvador pasa a ser la última ciudad del cobre tradicional en operaciones, así como María Elena es la última ciudad del salitre.

\section{Aspectos urbanos de las ciudades del cobre}

\section{Sewell: el campamento de montaña (Braden Copper Company, 1905)}

Sewell está localizado a $90 \mathrm{~km}$. al sur de Santiago (Chile), aproximadamente en el paralelo $34^{\circ}$, al oriente de la ciudad de Rancagua y a 2.100 m.s.n.m. en la Cordillera de los Andes, VI Región. Forma actualmente parte de la División El Teniente de CODELCO.
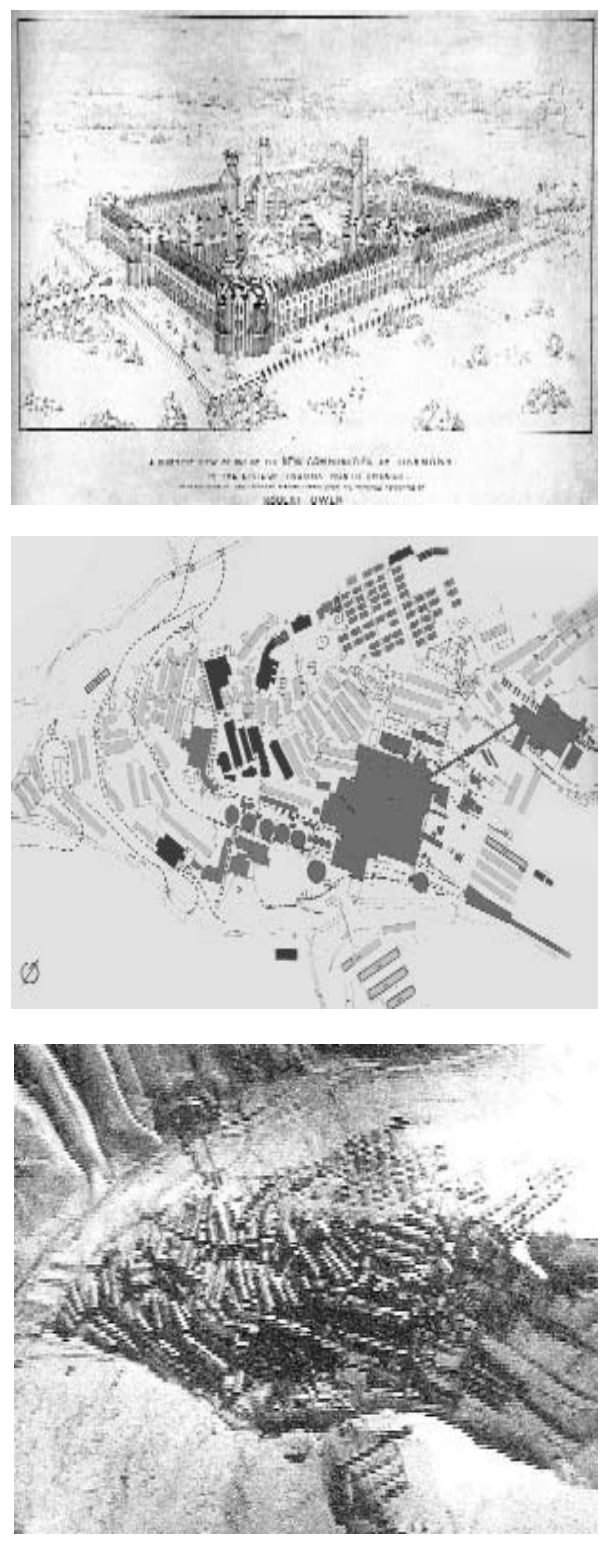
Sewell es el único ejemplo de asentamiento minero industrial de montaña en Chile. Estuvo poblado por cerca de 15.000 habitantes. Está situado en el Cerro Negro, cuya topografía y orientación son determinantes para la implantación de las edificaciones y el trazado de las vías peatonales, vehiculares y férrea. En la ladera norte se ubica la quebrada del río Coya y al sur, la quebrada del río Teniente. Perpendicular a esta última se encuentra la quebrada del Diablo, que conforma una ladera de pendiente pronunciada y escarpada. La disposición de Sewell en el Cerro Negro fortalece su presencia como sello distintivo de la División El Teniente. Para el observador no parece haber edificios paralelos ni en ángulos rectos, de manera que se percibe una fragmentación, al ascender, de los planos de las edificaciones, en un paisaje construido que refuerza la interioridad del espacio de la escalera central. Al descender, en cambio, se presentan planos de techumbres que parecen fugarse en el espacio geográfico. Las vistas cerradas y de perspectivas cortas dibujan el interior de la ciudad. El entorno se abre a las calles laterales en cuyo trasfondo los retazos de cordillera presentan la geografía, en dialéctica entre paisaje natural y paisaje construido.

La estructura urbana de Sewell está organizada a partir de la construcción de una gran escalera central por el espinazo del cerro Negro. Sobre la ladera norte se localizan preferentemente los edificios habitacionales, sobre la sur, los equipamientos e instalaciones industriales y en la quebrada del Diablo, la Población Sorensen, demolida en los años '70. La gran escalera central se constituye en el espacio público de mayor importancia. Distribuye hacia los costados por ramales de circulación, a modo de espina de pescado, paralelos a las cotas, para permitir accesos a las viviendas, equipamientos e instalaciones industriales. Enlaza con pequeñas plazuelas que se abren a su paso, desde el hito topográfico Penstock y la plaza Morgan, en la base, la plaza del Teatro en el centro, la plaza del Patinaje en el límite del campamento y la plaza del Obrero del Cobre, en la base de la estructura ferroviaria llamada Punta de Rieles. Los vehículos motorizados tienen acceso a los bordes del sistema peatonal, en tanto que el ferrocarril que conectaba con Rancagua -actualmente desmantelado- se abría paso entre las edificaciones, pasando junto a la fundición, hasta aproximarse a la parte baja de la Planta de Concentración.

Los edificios de viviendas fueron construidos a partir de tres distintas tipologías: de circulación externa, con unidades habitacionales similares a departamentos; de circulación central con corredor como elemento articulador lineal entre recintos; $y$ de circulación perimetral que permite el acceso a dos crujías de cuartos, sin servicios. Por su parte, en el barrio americano se construyeron viviendas unifamiliares aisladas, actualmente demolidas, dispuestas escalonadamente en la fuerte pendiente, a partir de su organización en
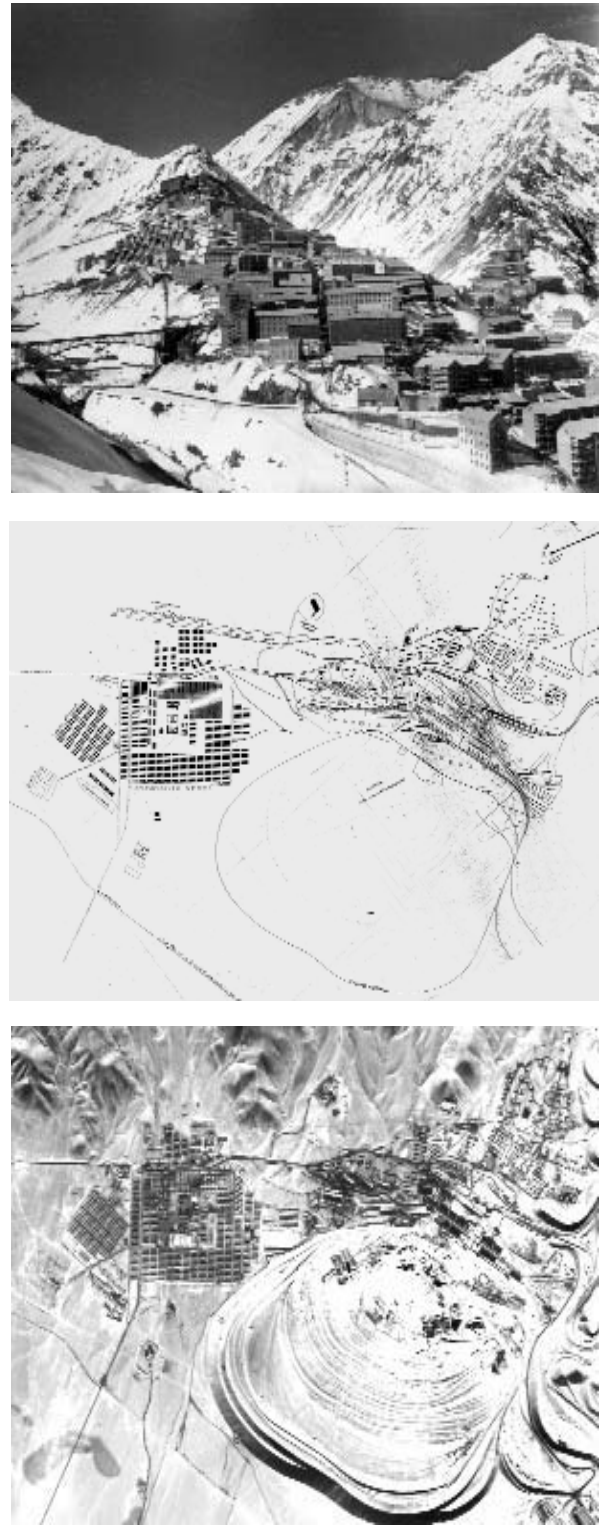
dos crujías paralelas a la cota.

Los edificios singulares se constituyen en hitos de referencia dentro del campamento. Un ejemplo es el Hospital, de planta compleja y volumetría destacada por su techumbre. En el costado sur del Cerro Negro se sitúa la Iglesia. Otro ejemplo de lenguaje moderno, es la Escuela Industrial, con tres niveles -además de piso zócalo- y una singular fachada curva y escalonada, despojada de ornamento. Por último, el Club Social Teniente, de aspecto neoclásico, aún subsiste en lo que fue el barrio americano, para alojamiento del personal norteamericano.

Entre las construcciones habitacionales destaca un edificio de vivienda colectiva (152), única edificación que se ubica contra la pendiente del cerro, con nueve plantas escalonadas, lo que le imprime una interesante presencia volumétrica. Entre las construcciones industriales destacan la estructura ferroviaria conocida como Punta de Rieles, ubicada en el punto más alto del campamento; el edificio de la Planta de Concentración, en la ladera sur del Cerro Negro, con sus cubiertas desplegándose en la pendiente; y el Puente Rebolledo, destinado al paso de la canoa de relaves.

La expresión arquitectónica resulta muy ajustada al tipo estructural, proceso constructivo y solución material: los sistemas en madera Balloon Frame y Platform Frame proporcionan el soporte a cubiertas de plancha de metal ondulado y paramentos de estucos sobre malla o plancha metálica, dispuestas directamente sobre la estructura.

A fines de la década del '60 Sewell inició un período prolongado de decadencia, relacionado con el traslado de sus habitantes a Rancagua, a partir de la llamada "Operación Valle" y la construcción de la Carretera del Cobre, en 1969 (Garcés, 1992). El total de la superficie demolida alcanza a las 18,8 há., equivalente a poco más de la mitad del área total, considerando zonas habitacionales e industriales. En este momento, la superficie total de Sewell es de $75.000 \mathrm{~m} 2$, de los cuales prácticamente la mitad corresponde a edificios habitacionales o de equipamiento, deshabitados y bajo condiciones de contaminación debido a la presencia de la fundición de Caletones, pocos kilómetros valle abajo. Es de destacar que en los últimos años, la División El Teniente ha realizado importantes avances en el control de emisiones.

El campamento ha sido objeto de un Plan de Acción Estratégico, fue declarado Monumento Nacional en categoría zona típica y pintoresca de la VI Región (1998) y habilitado como Museo Nacional de la Minería. En enero de 2005 fue presentada su candidatura como Sitio del Patrimonio Mundial ante la UNESCO.
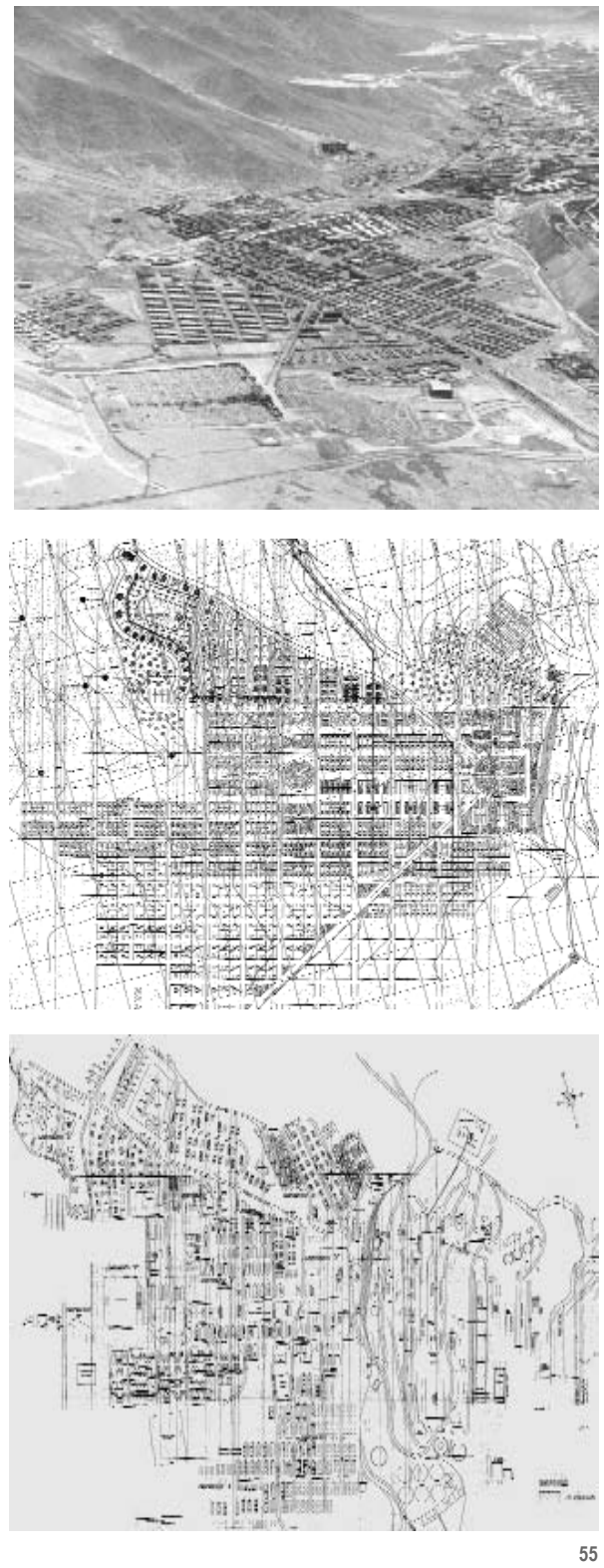


\section{Chuquicamata: el gran campamento minero (Chile Exploration Company, 1915)}

Chuquicamata está localizado a $1.600 \mathrm{~km}$. al norte de Santiago (Chile), entre los paralelos $22^{\circ}$ y $23^{\circ}$, $16 \mathrm{~km}$. al norte de la ciudad de Calama, $135 \mathrm{~km}$ en línea recta de la costa y a 2.780 m.s.n.m. en la II Región, en la depresión intermedia del desierto de Atacama, caracterizado por sus condiciones extremas de temperatura, alta oscilación térmica y radiación solar, sequedad del ambiente, escasas lluvias y fuertes vientos dominantes. Forma actualmente parte de la División Chuquicamata de CODELCO.

El asentamiento fue diseñado a partir de un campamento obrero de gran precisión formal, en forma de rectángulo de 600 por 800 metros aproximadamente, definido por dos ejes perpendiculares: un par nortesur que lo conectaron con la ciudad de Calama, y otro, oriente-poniente paralelo a la línea férrea, que lo vinculó con las instalaciones industriales y el barrio americano. El campamento estaba constituido por una retícula ortogonal presidida por una explanada central. Las calles remataban perpendicularmente con los ejes principales, para generar una óptima conectividad entre cualquier punto dentro de su área y estos ejes, de modo de favorecer la disminución del tiempo de transporte entre residencia y trabajo. La trama ortogonal se impuso de manera categórica al terreno, recordando los asentamientos urbanos españoles en América, aun cuando la manzana -propia del arte del buen establecer hispano- se desdibuja en favor del uso del bloque de viviendas en hilera, dispuestas de a pares con pasaje en medio, tipología de origen anglosajón. La localización del campamento obrero, a unos $2.000 \mathrm{~m}$. del acceso al sector industrial, posibilitó la construcción de villas de viviendas, elementos de equipamiento y espacios públicos entre ambos polos, a lo largo de la avenida Tocopilla.

La explanada central en cuyo centro se situó la plaza mayor -que data aproximadamente de 1911- permitió la disposición de los edificios de servicios y equipamientos más representativos. La explanada, de 70 por 170 metros, tiene una doble lectura dimensional: por una parte, la medida acotada por los límites que definen los edificios de equipamiento ubicados en sus bordes, conteniendo el espacio de la explanada; y por otra, la medida de la plaza construida, de una sexta parte de la explanada. Estas dos escalas, la de la plaza y la explanada en que se sitúa, constituyen un factor determinante del espacio más característico, centro fundacional y principal lugar de referencia de Chuquicamata. El ambiente de fuerte sol, viento y oscilaciones térmicas obligaron a favorecer el uso público intensivo interior de los edificios de equipamiento.

Entre el campamento obrero y el barrio americano, se construyó el hotel y el Hospital Chuquicamata, a partir de un proyecto realizado por la oficina neoyorquina de York \& Sawyer. Fue inaugurado en el año
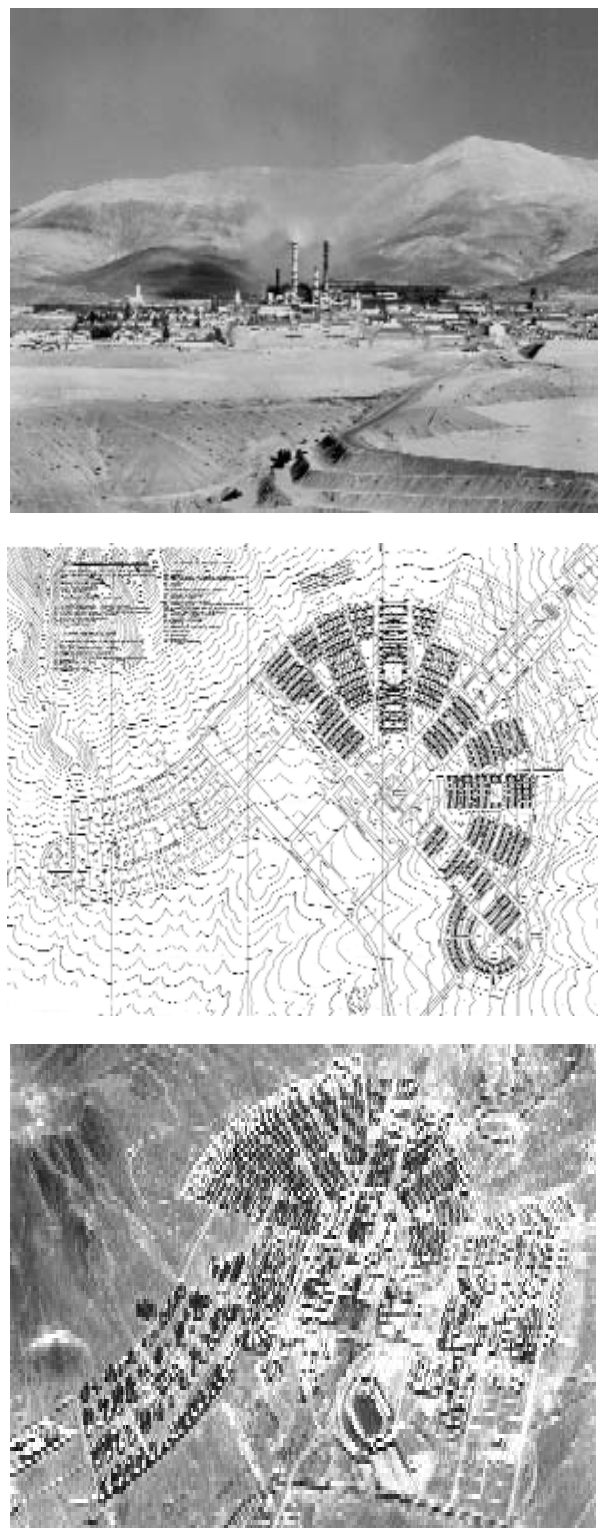
1962, con una capacidad de 250 camas.

Al término de la avenida Tocopilla fue levantado originalmente el barrio americano, muy cercano a la mina. Estaba formado por viviendas aisladas que iban ascendiendo en pendiente hasta la denominada "Casa 2000", del gerente general, Daniel Guggenheim. Más abajo se disponían las viviendas de supervisores, todas ellas adaptadas a la topografía y a las condiciones climáticas extremas del lugar, con propuestas paisajísticas que incluían especies vegetales como pimientos, pinos, palmas chilenas, etc. Fue el barrio americano más grande de su tipo en la minería chilena. En la década de los ' 80 se desalojó debido al avance de las tortas de ripios sobre el área. En su momento de auge estuvo habitado por cerca de 25.000 personas. Actualmente (2005) el campamento Chuquicamata está siendo desmantelado, de acuerdo con los lineamientos del "Proyecto Traslado", que implica el desalojo de todos los trabajadores y sus familias para ocupar nuevas viviendas en la vecina ciudad de Calama.

\section{Potrerillos: del proyecto barroco al campamento minero (Andes Copper Mining Corporation, 1919)}

Potrerillos está localizado a $1.130 \mathrm{~km}$. al norte de Santiago (Chile), entre los paralelos $26^{\circ}$ y $27^{\circ}$, a 150 km. del puerto de Chañaral y a 1.800 m.s.n.m. en la III Región, en la zona sureste del desierto de Atacama. Forma actualmente parte de la División Salvador de CODELCO.

Potrerillos fue construido a partir de un primer proyecto (1919) basado en un trazado de sistema abierto -tipo barroco- con dos grandes ejes diagonales y uno central, proyectados desde una plaza principal situada en el cabezal jerárquico del proyecto. Los ejes diagonales se concebían en forma indefinida, sin considerar el territorio y su topografía. Complementario con los ejes, el trazado era ortogonal, con manzanas de forma rectangular, con su lado mayor en contra de la pendiente, destinadas a las viviendas de los trabajadores, en contraste con el barrio americano, relativamente sinuoso, aprovechando las cotas del terreno. Los equipamientos fueron proyectados en torno de la plaza principal, situado en el punto más alto de la ciudad, vecina con el acceso al campamento que era la estación del ferrocarril, con un completo dominio visual del asentamiento. Al eje de la plaza principal, en el centro del campamento, se previó la existencia de otras plazas, y al norte, un eje de espacios públicos que separarían el barrio americano del resto del campamento.

En el campamento construido entre 1920 y 1927, el trazado del proyecto original fue adaptado a la topografía. Se rellenaron algunas quebradas con ripios resultantes del proceso industrial, de manera de
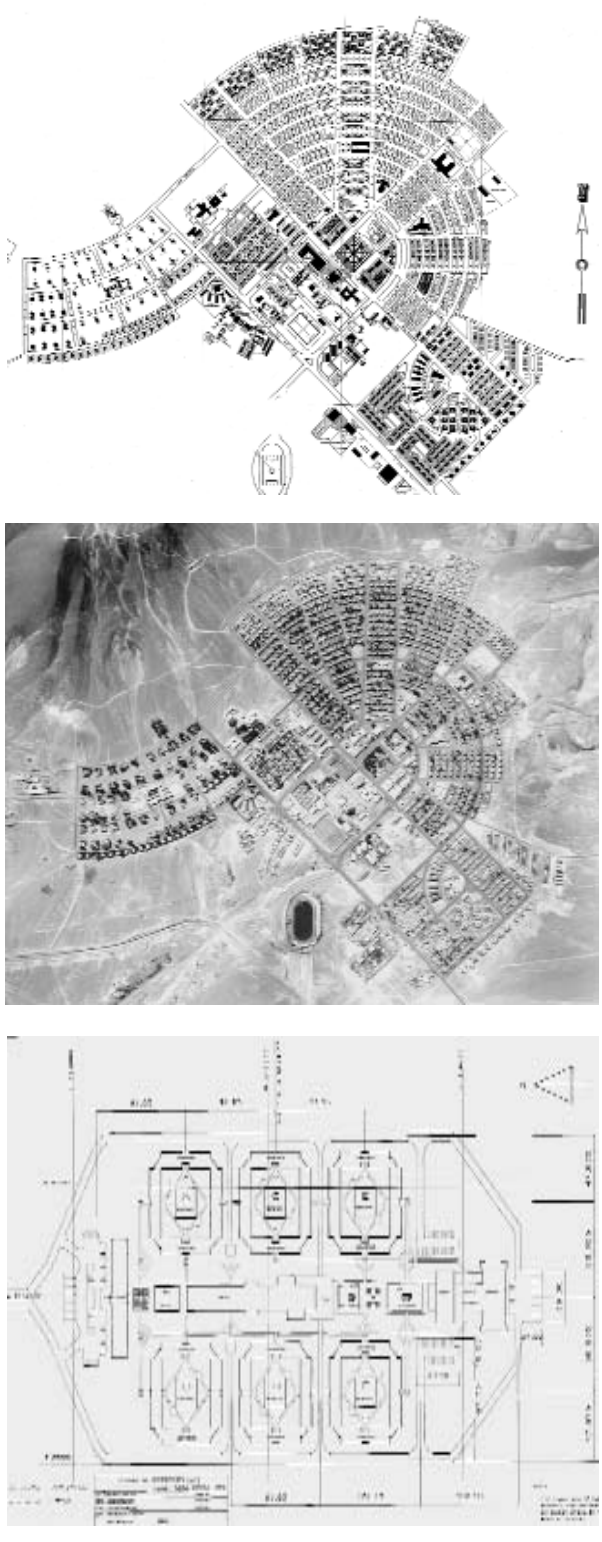
construir los bloques de vivienda de forma paralela a las cotas, con una disposición adecuada al soleamiento, consiguiendo orientar las fachadas de los bloques en dirección oriente y poniente. El sector industrial fue situado al este del campamento, más arriba de las líneas del ferrocarril y la estación. Junto a ella se ubicaron el retén de carabineros, la escuela, la oficina del telégrafo y correos, la pulpería y el banco. La plaza, de 140 por 120 metros, no pasó de ser un vacío urbano en pendiente, definido por algunos edificios de equipamiento. El resto del equipamiento se distribuyó por otros sectores del campamento: hacia el poniente de la plaza, el hotel, el edificio de sindicatos, el jardín infantil, el club, el teatro y el estadio, entre otros; hacia el sur, el estadio techado y el mercado público; y como parte del barrio americano, el hospital, un colegio, un club de golf y de tenis.

Dos tipologías de vivienda tuvieron mayor presencia: la pareada, que se encuentra principalmente en el barrio americano y en el sector norte alto, ambas presentes hasta hoy; y otra en hilera, que constituyó un tipo de edificación capaz de agrupar en forma flexible distintas organizaciones espaciales. Tras el terremoto de 1968 se construyeron nuevos barrios que reemplazaron las áreas inhabilitados por el sismo. Hacia 1971 se construyó el nuevo acceso vehicular desde el sector poniente y a lo largo de la avenida Prat, complementario y luego sustituto del ferrocarril como forma de acceso al campamento. Este acceso permitió la implantación de nuevos equipamientos, constituyendo un centro lineal complementario de los edificios de equipamiento situados en torno a la plaza central. En 1997 se construyó una nueva plaza al centro del campamento, mediante terrazas y escaleras, cuando la decisión de cierre del campamento estaba prácticamente tomada, en atención a que fue declarado zona saturada de contaminación. En consecuencia, el campamento fue cerrado en 1997 -no así la planta industrial- y la población trasladada a El Salvador y otros lugares próximos como Diego de Almagro, Llanta y Copiapó.

\section{El Salvador: el campamento moderno (Andes Mining Copper Company, 1959)}

El Salvador se localiza a $1.100 \mathrm{~km}$. al norte de Santiago (Chile), entre los paralelos $26^{\circ}$ y $27^{\circ}, 32 \mathrm{~km}$. al norte de Potrerillos, a 2.300 m.s.n.m., $110 \mathrm{~km}$ de la costa y a $55 \mathrm{~km}$ al noreste de Diego de Almagro, en la III Región, límite sur del Desierto de Atacama. Forma actualmente parte de la División Salvador de CODELCO.

El Salvador designa al nuevo yacimiento encontrado en 1954 a $2.400 \mathrm{~m}$. de altura, al oeste de la sierra del Indio Muerto, y en particular, al lugar planificado para la función habitacional. El campamento fue
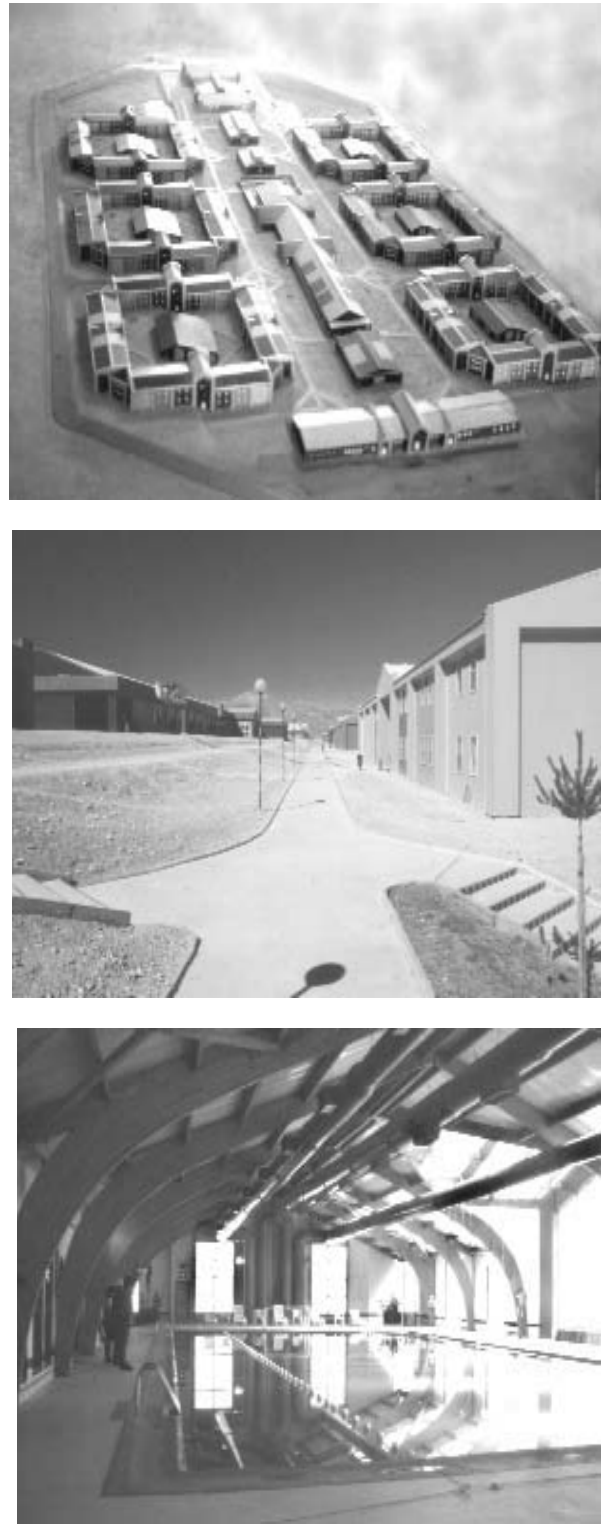
proyectado por Raymond Olson (arquitecto, New York), considerando la construcción de 1.200 viviendas para alojar a 6.500 personas, lo que da un promedio algo superior a cinco personas por vivienda, densidad adecuada para un campamento modelo, incluyendo disposiciones de carácter social para sus trabajadores, al alero del New Deal -propuesta de desarrollo económico para Latinoamérica por Estados Unidos- que incorpora conceptos de calidad de vida descrita en términos de good living, health and recreation. La memoria de proyecto del arquitecto Olson (1958) es clara en este sentido, recordando las propuestas del Team 10 y las primeras New Towns:

1. El diseño curvo fue realizado para evitar la monotonía desplegada en muchos campamentos organizados con una estricta retícula de damero.

2. El campamento fue situado en un anfiteatro natural. El terreno se eleva gradualmente desde el punto focal del semicírculo hacia los bordes del campamento, en un ascenso gradual aproximado de $27 \mathrm{~m}$, en una distancia de $600 \mathrm{~m}$.

3. El Salvador es una 'comunidad peatonal' en la cual los equipamientos como centro comercial, lugares de reunión, oficinas públicas e iglesia cerca de la plaza, se encuentran a una distancia fácil de caminar desde todas las viviendas.

4. Las áreas de recreación y equipamientos están localizados en áreas apropiadas por su cercanía con los vecindarios y distribuidas de manera uniforme.

5. El transporte de empleados y obreros a la mina se realiza de la manera más conveniente posible para todos los usuarios. Son apreciables los numerosos paraderos de buses en el arco semicircular, situado en el centro.

6. Con propósitos de seguridad para los niños pequeños, las escuelas fueron dispuestas lejos de las áreas de tráfico, de manera que los niños pueden ir hacia y desde el colegio por áreas de menor flujo de tráfico, en la periferia del campamento.

7. El hospital está situado a mano de todas las áreas residenciales.

8. Se han usado 10 diferentes colores pastel, compatibles entre sí, para decorar las viviendas, de modo de evitar toda apariencia de monotonía.

9. También se ha evitado la monotonía variando el diseño de las viviendas unifamiliares. Fueron diseñados cuatro tipos de viviendas, cada uno con diferentes modelos de tres y cuatro habitaciones.

10. La combinación de colores pastel en los muros con techos de un blanco brillante (para reflejar el calor)
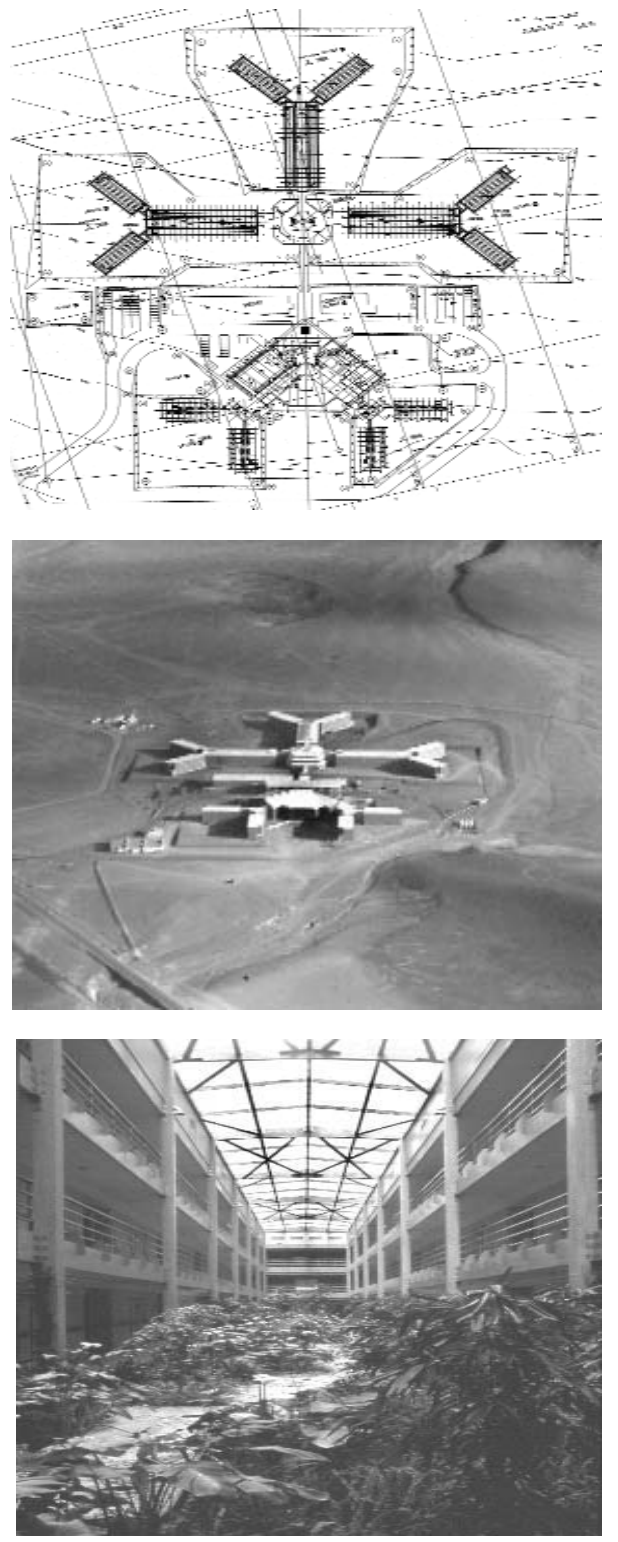
pretende otorgar a El Salvador una apariencia semejante a las casas blancas y rosadas de techo blanco que exhiben las viviendas de Las Bermudas. La apariencia de El Salvador va a estar realzada por el hecho que las viviendas se dispondrán en una serie gradual de crecientes semicírculos, desde la plaza hasta los bordes del campamento".

El Salvador fue proyectado con precisión formal y funcional, a partir de un trazado geométrico de anillos concéntricos siguiendo la forma de un anfiteatro, que recuerda al casco minero, y un programa de ingeniería social especificado en detalle. El proyecto planteaba un orden geométrico de semicírculos concéntri$\cos$ de $180^{\circ}$ desde la plaza como foco de la composición. Sobre el semicírculo central convergen un par de avenidas diametrales y sendas avenidas perpendiculares a las anteriores, que rematarían en el extremo superior del campamento, donde se proyectó el equipamiento deportivo.

Estos pares de ejes se complementaban con avenidas a $45^{\circ}$, que alcanzan el semicírculo, y avenidas complementarias, dando lugar a triángulos destinados a espacios públicos y edificios de equipamientos. Hacia el oeste el proyecto se prolonga para dar origen al barrio americano. Entre estas dos formas urbanas, bien definidas, aparece un amplio espacio central, de grandes manzanas libres, adyacente al sur de la plaza y que separa ambos sectores residenciales. Finalmente, un semicírculo más pequeño, dispuesto en el extremo suroriente de la composición, cierra el conjunto de avenidas semicirculares, equilibrando la geometría del proyecto. El equipamiento dispuesto en el centro, en torno a la plaza, corresponde a oficinas públicas, bancos, restaurantes y área comercial. Los servicios de carabineros, bomberos y hospital fueron proyectados en el espacio central. Para potenciar el carácter peatonal del campamento se crearon otras plazas dispuestas a lo largo de la avenida principal y en el barrio americano.

En diciembre de 1966 ya eran apreciables los cambios respecto del proyecto original. El campamento había crecido hasta 12.000 habitantes, hecho que hizo aumentar el programa de equipamientos y de viviendas en base a soluciones que en parte han desdibujado el proyecto original y su trazado concéntrico ajustado y preciso. Se han obviado parcialmente sus leyes básicas, presionadas por el crecimiento del campamento, la existencia de una quebrada que el proyecto no consideró, el establecimiento de nuevas edificaciones, cambios en los usos urbanos de avenidas y accesos, desarrollo informal del gran espacio vacío central cuya ocupación no previó el proyecto original, ampliaciones y transformaciones de las viviendas (Ortúzar et al., 2000). 


\section{San Lorenzo: la villa minera (Compañía Minera Escondida Limitada, 1995)}

La villa minera San Lorenzo, de Minera Escondida, está localizada a $1.550 \mathrm{~km}$. al norte de Santiago (Chile), aproximadamente en el paralelo $24^{\circ}$, a $220 \mathrm{~km}$ de la ciudad de Antofagasta y a 3.150 metros de altura., en la II Región, en pleno desierto. Forma parte de la Compañía Minera Escondida Limitada.

La experiencia acumulada por las empresas pioneras, en los asentamientos ya señalados, permitió a los nuevos emprendimientos mineros privados una nueva formulación del problema y de la tipología del asentamiento. La compañía Minera Escondida (1990) planteó el concepto de villa minera, como es el caso de San Lorenzo (1995), conjunto de edificios agrupados en forma de manzana alineados a lo largo de un eje de equipamientos, diseñado para albergar a trabajadores -sin familias- en régimen de turnos, situado a una cierta distancia visual y funcional de las instalaciones industriales. La Villa San Lorenzo es la materialización física de una política que enfrentó con una perspectiva distinta el tema de las construcciones de habitación y servicios para su personal, como resultado de un esfuerzo conjunto entre profesionales de la propia compañía minera, la oficina de arquitectura Pfenninger y Sologuren y la empresa constructora. La noción de campamento, tradicional en el ambiente minero, fue sustituida por la de villa, intentando caracterizar nuevas relaciones laborales que fuesen capaces de reemplazar con eficacia a los campamentos analizados más arriba, asumiendo toda la experiencia acumulada por 80 años de asentamientos mineros del cobre. Desde el punto de vista habitacional, la compañía estableció dos focos: en el área de operaciones desarrolló tres campamentos para el personal en faenas, y para los trabajadores y sus familias construyó conjuntos de viviendas en Antofagasta.

Los campamentos corresponden al Campamento mina, con capacidad para 1.000 personas; el Campamento 2000, para contratistas, con capacidad para 2.000 personas; y la villa San Lorenzo, para 2.000 personas. Estos dos últimos se localizan a unos cinco kilómetros de la mina.

La Villa San Lorenzo corresponde, de acuerdo con las definiciones de las nuevas empresas mineras, al campamento de operación, que consiste en instalaciones construidas para albergar al personal que opera la mina durante el proceso de explotación minera e industrial. Es un conjunto de tres manzanas de dormitorios y servicios, de 50 por 50 metros por lado, con un patio interior de 26 por 26 metros, dispuestos a uno y otro lado de un bloque central alargado que contiene los distintos equipamientos y servicios. Al interior de cada manzana hay un edificio aislado con programa comunitario, salas de juego, estar y baños. Las manzanas están formadas por dos crujias de dormitorios y baños, a uno y otro lado de un largo pasillo. Las 
esquinas se formalizan mediante la continuidad del pasillo. Junto a los accesos, caracterizados por un tímpano triangular, se sitúan las escaleras y el ingreso al patio interior.

El bloque central está constituido por los principales recintos de equipamiento, formando la columna vertebral del conjunto, con servicios independientes, utilizables en horarios diferentes y accesos diferenciados: casino, gimnasio, piscina, capilla católica y evangélica y oficinas generales. Este bloque central se encuentra flanqueado por espacios longitudinales, a la manera de avenidas peatonales descubiertas, que permiten la circulación hacia los núcleos de dormitorios a la vez que el tránsito entre ellos y el eje central.

El programa de la villa fue estudiado en relación con un sistema de turnos rotativos de 4 por 4 días, divididos en cuatro grupos. Cada turno corresponde a cuatro días de trabajo, alojando en el campamento y cuatro días de descanso, en la ciudad de Antofagasta.

Este sistema de turnos permite que siempre coexistan dos grupos en la villa: uno en el turno de día y otro en el de noche, por lo que la intensidad de uso de los espacios comunes es escasa, tanto de las manzanas como del bloque central, considerando un máximo de cuatro horas disponibles para la utilización de los espacios recreativos y de servicio.

\section{Portal del Inca: el hotel minero (Compañía Minera Doña Inés de Collahuasi, 1999)}

El Hotel Minero Portal del Inca está localizado a más de $2.000 \mathrm{~km}$. al norte de Santiago (Chile), poco al norte del paralelo $21^{\circ}$, a $185 \mathrm{~km}$. al sureste de la ciudad de lquique, a una altura de 3.850 m.s.n.m., en la I Región, en un ambiente desértico de altura. Forma parte de la Compañía Minera Doña Inés de Collahuasi.

La compañía minera fue organizada en función de tres focos de operación. El primero de ellos es el complejo minero y residencial Portal del Inca, situado en el área del Salar de Ujina, al que se accede desde Iquique por un camino de $185 \mathrm{~km}$. y un aeródromo. Lo conforman los tres yacimientos cupríferos (Ujina, Rosario y Huinquintipa), donde se realizan operaciones de extracción y procesamiento del mineral. El segundo foco es el puerto de Punta Patache, $70 \mathrm{~km}$. al sur de lquique, donde se embarca la producción de concentrado de cobre, transportada desde la mina mediante un mineroducto de $200 \mathrm{~km}$. de extensión. El tercero lo constituye la ciudad de lquique, donde se construyeron dos condominios de viviendas.

La compañía minera y los arquitectos Correa 3 propusieron un cambio radical en el concepto y tipología de campamento, considerando las nuevas ideas introducidos por Minera Escondida. Había que adop- 
tar nuevos estándares en la disposición de funciones y espacios, para generar un ambiente que pudiese aminorar al máximo la falta de confort físico y psíquico, producto de las condiciones ambientales desérticas de altura, y promover las relaciones interpersonales entre los trabajadores y empleados para interactuar con el medio laboral de manera positiva. Para ello se proyectó una nueva tipología residencial, distinta del campamento y de la villa, más ajustada a las nuevas modalidades de relaciones laborales y con mayor eficiencia en el uso del tiempo laboral y recreativo. La propuesta fue la de un hotel minero, unidad integral y compacta, que evoca ideas asociadas con lo temporal y lo provisorio -relacionado con el sistema de turnos- y sugiere estándares de calidad vinculados con la hotelería, bien caracterizada formalmente, con espacios interiores acondicionados, servicios integrales y uso eficiente de las instalaciones.

Desde un punto de vista constructivo se adoptó un criterio semejante al utilizado por Minera Escondida, es decir el de módulos prefabricados, en este caso de 3.60 por 13.30 metros, transportados en camiones desde Santiago hasta la obra. A diferencia con la villa San Lorenzo, los módulos se dispusieron en forma perpendicular al plano de fachada, en tres pisos de altura.

El conjunto presenta una estructuración cruciforme, con un edificio de tres alas destinadas a habitación y una cuarta, separada de las anteriores, que comprende los principales servicios del conjunto. La separación permite generar entre los dos cuerpos el acceso al conjunto, controlado visualmente, que da la idea de abrigo frente a la vastedad característica del paisaje. El punto central y de mayor uso dentro del conjunto lo constituye el espacio de ingreso hacia los edificios principales de dormitorios y de servicios. Ofrece todo lo necesario para la vida del personal en faena, su alimentación, descanso y distracción, incorporando vegetación a los interiores, en contraste con el paisaje exterior de desierto, montañas y salares. Los dormitorios se dispusieron en pabellones longitudinales que permiten a los trabajadores el recorrido por el edificio para llegar al comedor. En ese recorrido cruzan los jardines interiores, situados en un espacio de triple altura con iluminación cenital, y los espacios de esparcimiento, en un ambiente climatizado que permite el encuentro de las personas.

\section{Las ciudades del cobre como formas excepcionales del hecho urbano}

Un problema teórico que se presenta a la vista de los casos que se presentan es la capacidad de constituir ciudad que han tenido estas ciudades del cobre. Porque si comparecen como asentamiento minero, campamento minero, villa minera y hotel minero, ¿bajo qué concepto los inscribimos? Un ejemplo es 
Chuquicamata, el caso más grande en tamaño, número de habitantes y complejidad de los que se presentan en este artículo, y que sin embargo se encuentra en proceso de desmantelamiento, por lo que no cumple con uno de los atributos de la ciudad, cual sería su permanencia en el tiempo.

Todo proyecto de establecimiento humano implica trabajo, esparcimiento, circulación y residencia (Le Corbusier, 1957). Se reconoce en la ciudad una institución dotada de carga simbólica, un escenario del poder como lugar con significados compartidos, como representación de la sociedad en el espacio (Aymonino, 1972). Se establece como un asentamiento, relativamente grande y permanente, de población heterogénea, con funciones diversas, autarquía y territorio propio (Munizaga, 1997). Una de sus aspectos centrales es la continuidad que caracteriza a los hechos urbanos (Rossi, 1976).

De este modo, el hecho urbano viene a estar determinado por sus aspectos funcionales, simbólicos, materiales y formales, su vitalidad compleja e intensa y -desde luego- su permanencia en el tiempo

En nuestro caso, la idea de asentamiento parece la más adecuada para definir el conjunto complejo de funciones y edificaciones de viviendas, edificios de equipamiento e instalaciones industriales, organizadas por sistemas de trazado que le permiten su organización interna, al mismo tiempo que la articulación con el resto de los elementos y centros poblados del territorio. El concepto de campamento estaría asociado a una forma menor en sus dimensiones físicas, ambiciones temporales y complejidad funcional, que incluye las funciones y construcciones relacionadas con la residencia y su ubicación a modo de satélite de una ciudad mayor (Sargent, 1990).

El interés de los casos que se han presentado radica en que, en tanto asentamientos industriales y en particular mineros, son manifestaciones de un modo de hacer ciudad derivada de la company town, que ha permitido la ocupación productiva de territorios complementarios. Esta ocupación productiva se ha realizado a partir de tipologías edilicias y morfologías urbanas que han ido evolucionando a lo largo del siglo XX, desde ejemplos surgidos en el ámbito de la Revolución Industrial hacia nuevos modelos, relacionados con el contexto productivo, geográfico, espacial e histórico en que se sitúan. Son paradigmas para la comprensión del problema más genérico de un modo de habitar segregado respecto de la sociedad y las ciudades tradicionales, relacionados con actividades extractivas y productivas, dependientes de una administración empresarial centralizada. Los ha habido con poblaciones que superan los 20.000 habitantes en momentos de apogeo, han tenido una fuerte identidad y complejidad urbana, fueron construidos con tecnologías de avanzada, formaron parte de un sistema con amplias repercusiones en los territorios y han carecido de per- 
manencia en el tiempo.

La noción de asentamiento minero permite caracterizar algunos casos, como Chuquicamata y Potrerillos, por la fuerte relación entre campamento e industria. El Salvador, al no estar relacionado con un área industrial, se asocia con la idea de new town minera. El campamento de montaña es una variante de la categoría anterior, con una fuerte componente geográfica que determina su organización, haciéndola singular, como es el caso de Sewell. Villa San Lorenzo y Hotel Portal del Inca, los ejemplos de construcción más reciente, se caracterizan por tener edificaciones unitarias y homogéneas que conforman un complejo mayor. San Lorenzo permite hacer de puente entre la idea de campamento y de hotel. El hotel minero marca una clara ruptura respecto de los casos tradicionales, pudiendo leerse como una máquina de habitar que recuerda paradigmas modernos.

De este modo, las empresas mineras privadas propusieron, a fines del siglo $\mathrm{XX}$, una estrategia que supone una polarización y desagregación del modelo, a partir del progreso en los sistemas de comunicación en todos sus niveles: mejores vías, nuevos sistemas de transporte de carga y pasajeros -al tren se agrega el autobús y el camión y finalmente los ductos mineros- y el avance de las telecomunicaciones; el manejo de los aspectos ambientales, que empiezan a regular cada vez más las condiciones críticas de vida en los asentamientos mineros chilenos, con altos índices de contaminación generados por la industria; la superación del esquema de company town que obligaba a la prestación de servicios para sus habitantes trabajadores y familias. La separación de funciones implica un descargo en los gastos generados por estos servicios, entregados por ciudades próximas, funcionales a los intereses industriales, las que asumen o a lo menos comparten gran parte de estos costos. La noción de industria -company- es relacionada con las instalaciones industriales y obras de infraestructura vinculadas con la extracción, procesamiento, transporte y embarque del producto. La idea de pueblo o poblado -town- toma dos direcciones: primera, la villa $u$ hotel para el alojamiento, relacionado, pero a una cierta distancia, de la industria, en sistema de turnos; $y$ segunda, condominios para las familias de los mineros -obreros, empleados, técnicos, ejecutivos- en una ciudad vecina.

A fines del siglo XX, la villa minera y el hotel minero han terminado reemplazando a la ciudad minera, reemplazo que no significa olvido, ya que las ciudades del cobre han representado unas formas específicas -sociales, culturales, productivas- de hacer ciudad, de vida urbana, de producción de materias primas, que les ha permitido incorporarse con derecho propio al ideario nacional, reconociendo en ellas una formas 
de vivir y producir que han aportado las principales bases de sustentación económica del país durante el siglo XX.

Sin embargo, y como muchas veces ha ocurrido, el valor de estos asentamientos, en términos de patrimonio cultural, se ha aquilatado cuando ya se han producido los desalojos y se han iniciado los procesos de desmantelamiento. La conciencia histórica nacional respecto de su valor como patrimonio ha sido escasa, sobre todo considerando que las políticas de relaciones públicas de las empresas mineras normalmente han enfatizado las ventajas del cambio de escenario como un hecho positivo, que señala las bondades de la nueva destinación y subraya las desventajas del antiguo asentamiento antigüedad del parque habitacional, contaminación, desvinculación del país real, etc. La nostalgia de los residentes, recogida en su momento por alguna prensa local, ha sido utilizada más como herramienta de presión para conseguir mejores beneficios que para salvaguardar ese patrimonio. De esta manera y casi exclusivamente en medios académicos se ha estudiado y puesto en valor los contenidos patrimoniales que reúnen estas company towns del cobre. De hecho un estudio sobre Sewell, realizado en la Universidad Católica de Chile, fue pionero en estas materias y abrió paso para que la división El Teniente y la Comisión de Monumentos Nacionales presentasen el expediente, en enero de 2005, para que fuese postulado ante la Unesco como Patrimonio de la Humanidad. Potrerillos, a su vez, fue objeto de otro estudio destinado a preservar el campamento. De Chuquicamata se pretende conservar la plaza y edificaciones adyacentes, como testimonio y memoria del que fue el campamento más grande de la minería chilena. La presentación de Sewell ante la UNESCO abre nuevas perspectivas respecto de la valoración de unos asentamientos industriales en tanto piezas de valor patrimonial, más allá de su consideración como meros artefactos productivos, en un país como Chile de larga tradición minera, de manera que se comienza a aquilatar la contribución de estos asentamientos al arte del buen establecer en territorios complementarios y los pone en perspectiva como paisajes culturales.

\section{Referencias bibliográficas}

Aymonino, C. (1972). Orígenes y desarrollo de la ciudad moderna. Barcelona. Gustavo Gili.

Dal Co, F. (1975). "De los parques a la región". Ciucci, G. et al., La ciudad americana de la Guerra Civil al New Deal. Barcelona. Gustavo Gili.

Garcés, E. (1999). Las ciudades del salitre. Santiago. Orígenes. 
Garcés, E. et alt. (1992). "Sewell asentamiento minero (1904 hasta la actualidad)". Arquitectura Panamericana, 001. 104-117.

(2001). "Los campamentos de la minería del cobre en Chile (1905-2000)". Informe final Proyecto Fondecyt 1990485.

Le Corbusier (1957). La Charte d'Athènes. Paris. Points Essais.

Olson, R. (1958). "Memoria proyecto El Salvador". Engineering and Mining Journal, 159, 11.

Ortúzar, P. et al. (2000). "Las viviendas de El Salvador". Taller de Investigación Asentamientos mineros del cobre en Chile, $2^{\circ}$ semestre 2000. Santiago. Escuela de Arquitectura, PUC.

Morris, A. E. J. (1984). Historia de la forma urbana. Desde sus orígenes hasta la Revolución Industrial. Barcelona. Gustavo Gili.

Munizaga, G. (1997). Diseño urbano, teoría y método. Santiago. Ediciones Universidad Católica.

Reps, J. W. (1965). The making of Urban America. A history of city planning in the United States. Princeton, New Jersey. Princeton University Press.

Rossi, Aldo (1976). La arquitectura de la ciudad. Barcelona. Gustavo Gili.

Sargent, L. (1990). "Campamento de Exploración". Revista ARQ, 15. 